\title{
Augmented Reality Task Guidance for International Space Station Stowage Operations
}

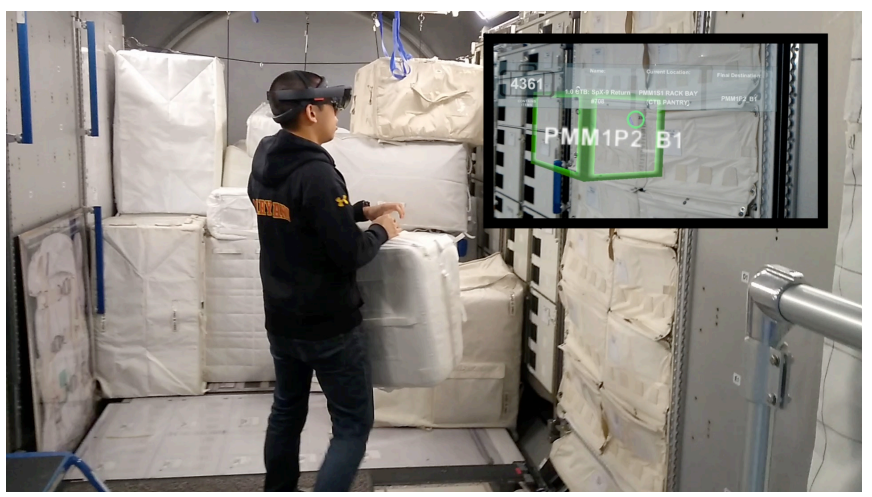

\author{
Hiroshi Furuya, Lui Wang, Carmine Elvezio, \\ Steven Feiner
}

Built at NASA Johnson Space Center (JSC) and Columbia University and tested in JSC's full-scale mockup of the International Space Station (ISS), StowageApp is a prototype for the future of conducting cargo operations in space. StowageApp dynamically guides astronauts as they complete stowage tasks, packing and unpacking cargo. 